\title{
The translation and use of green infrastructure evidence
}

1 Danielle Sinnett BSc(Hons), PGCert, MSc, PhD Senior Research Fellow, Centre for Sustainable Planning and Environments, University of the West of England, Bristol, UK (corresponding author: danielle.sinnett@uwe.ac.uk) (Orcid:0000-0003-4757-3597)

2 Tom Calvert BMus, MSc, PhD

Research Associate, Centre for Sustainable Planning and Environments, University of the West of England, Bristol, UK

3 Nick Smith BSc(Hons), PGCert, MPhil, MRTPI, FRGS Associate Head of Department, Centre for Sustainable Planning and Environments, University of the West of England, Bristol, UK
4 Sarah Burgess BRTP(Hons)

Senior Lecturer, Centre for Sustainable Planning and Environments, University of the West of England, Bristol, UK

5 Louise King MA(Hons), MSc, MRICS

Senior Lecturer, Centre for Sustainable Planning and Environments, University of the West of England, Bristol, UK
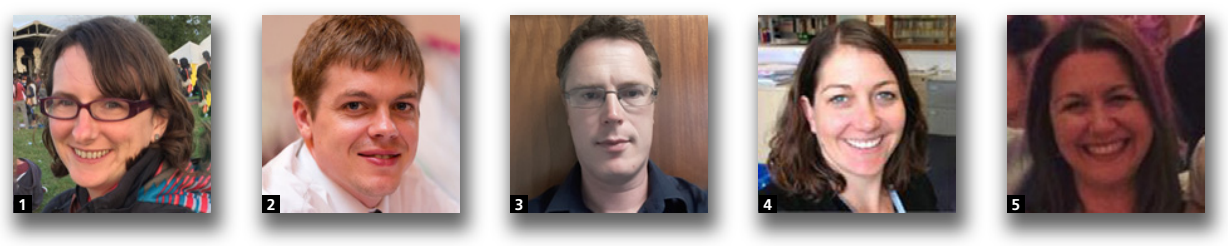

The success of green infrastructure (GI) depends on the sharing of good practice and research between disciplines and sectors. This paper presents findings from a study to examine how GI research is shared with non-academic audiences. GI has been an active research area in recent years, with a wealth of evidence coming from the academic community. This has been mirrored by a body of grey literature aimed at different disciplines and sectors. But it is important to understand which evidence is being used in this grey literature and what the gaps are either in research or in its translation. In this study, 25 pieces of grey literature were reviewed to identify what research is represented; presented as the benefits or ecosystem services provided by different types of GI. This review was presented to around $\mathbf{7 0}$ academics, policy makers and practitioners working in Gl through two workshops. Attendees were asked questions in order to further understanding of how research is translated and used, and the mechanisms by which it can be more effectively shared. The paper provides insights into how those working in GI can work collaboratively to ensure research findings are relevant and usable.

\section{Introduction}

There are numerous definitions of green infrastructure (GI) from various sources. Those adopted by the European Commission and UK governments have significant commonalities in terms of the characteristics of GI (DCLG, 2016; EC, 2013; NRW, 2015; Scottish Government, 2011).

- It is a network of different features including greenspaces, parks, open spaces, playing fields, woodlands, street trees, allotments, private gardens, wetlands, streams and other water bodies, green roofs and walls that are often linked to other components including transport and drainage infrastructure.

- It is multi-functional, providing a range of benefits or ecosystem services (to people/communities) both now and in the future.

- It is primarily urban or peri-urban, although it can be rural, but should provide connectivity between the built environment and the countryside.

- It is planned and developed strategically.
GI has been the subject of considerable research in recent decades. First, this research was focused on the benefits of various individual components, for example parks and street trees (e.g. de Vries et al., 2003; Freer-Smith et al., 1997), and it then considered integrated or multi-functional networks, for example, in improving air quality or nature conservation (e.g. Kazemi et al., 2011; Tallis et al., 2011). However, the benefits it provides are dependent on its successful delivery, which can be more difficult to achieve in practice. Therefore, more recently, research interests have broadened to include the planning, governance and long-term maintenance of GI (Jerome, 2017; Mell, 2014). This has been paralleled with a considerable effort to translate this research into a format more relevant to practitioners and policy makers, often as 'grey literature'. Much of this has been written by particular organisations either targeting a specific audience (e.g. planners) or promoting a particular benefit (e.g. health, nature conservation) or a component of GI (e.g. trees). Grey literature is defined as

that which deals with the production, distribution, and access to multiple documents types produced on all levels of government, 
academics, business and organisation in electronic and print formats, not controlled by commercial publishing (GLNS, 2012).

It is often seen as a way of communicating with policy makers, practitioners and the public in an accessible format (Lawrence et al., 2014). GI grey literature might include technical reports, literature reviews, position or briefing papers and guidance. Often these contain case studies from research or practice. As well as publications there are also websites and other tools for GI.

However, it is not clear whether this grey literature is used in practice, who is using it and for what purpose. It is also important for researchers to understand the type of evidence that is prioritised for practitioners and why, as well as whether its format and content meets practitioners' needs.

The aim of this study was to examine how the evidence base for GI is being translated for the practice community. This was explored through an examination of the evidence presented in grey literature, and its use by, and usefulness for, the GI community.

\section{Scope and approach}

\subsection{Review of grey literature}

A sample of GI-related grey literature was reviewed. The review sought to examine the extent to which academic research is translated into grey literature and identify the key disciplines, sectors and networks involved in the translation and sharing of GI research. Therefore, the focus was on grey literature presenting evidence related to GI generally or some aspect of it (e.g. trees, greenspaces) aimed at a non-academic audience that draws on evidence from the academic literature. A substantial body of grey literature, including literature reviews, summaries of evidence and guidance, was found so the following criteria were used to prioritise documents from an initial list of 111 documents.

- The document must contain references.

- It must be aimed at a UK audience, as opposed to providing evidence related to specific locations. The only exception to this was the work of Bowen and Parry (2015), which provides a very recent and thorough analysis of the health and wellbeing evidence.

- To provide a set of documents representative of a range of organisations for different disciplinary audiences.

- It must focus on GI in the urban environment (although Rolls and Sunderland (2014) and Sunderland (2012) consider the benefits of investing in the natural environment more generally).

- It must have been available for download from the internet at no cost by 28 February 2016.

In total, 25 pieces of grey literature were reviewed from 21 different authors or organisations (Table 1). These included 12 literature reviews, six guidance documents, two evidence summaries, five documents that are a mix between evidence summaries and guidance, and one that is an evidence summary with some primary research (CABE Space, 2010). Grey literature presenting only primary research (e.g. technical reports) was excluded as the purpose of the review was to examine the translation of academic evidence. Although included in the review as they provide references, four documents (GLA, 2015; Landscape Institute, 2015; NWGITT, 2008; Shackell and Walter, 2012) either did not cite academic evidence or the evidence was not attributed to sources, so these are not discussed further.

The review was framed using a typology of GI features and the ecosystem services they can deliver. The evidence cited in the grey literature was organised by feature (e.g. street trees, greenspace), then by the ecosystem services delivered by these features (Table 2). Ecosystem services are used to describe the goods and services, or benefits, provided by nature to human health and wellbeing (UKNEA, 2011). However, as it presupposes the existence of 'nature', the benefits that GI might provide to nature conservation and biodiversity are summarised separately. Similarly, often the next step in the assessment of ecosystem services is an economic valuation of these services so this evidence is also summarised separately. The disciplines, sectors and networks involved in the publication of this grey literature were also examined, as were any gaps in research or translation of research.

No assessment was made of the quality of the evidence or the accuracy of its interpretation in the grey literature; the purpose was solely to identify the subject and type of evidence that is presented in such literature. Only instances where documents cited evidence from primary sources of academic literature were included in the findings; for example, some of the documents referenced other grey literature.

The review allowed a series of questions to be formulated that were then presented to the GI community to supplements the findings.

\subsection{Incorporating the views of the GI community} Two workshops, in Birmingham (England) and Glasgow (Scotland), were run in order to gain further insight into GI practices and their relationship with academic research. These brought together the GI community of research, policy and practice.

The findings from the review were presented to the participants and two interactive sessions allowed participants to share their knowledge and experiences. The first session was used to consider a series of ten questions developed from the key findings that could be answered relatively quickly with little discussion. Some of these questions were developed more fully in the later session; others were more simplistic in nature. The second 
Table 1. Grey literature included in this review

\begin{tabular}{|c|c|c|c|c|c|c|}
\hline Title & Year & Organisation (reference) & $\begin{array}{l}\text { Literature } \\
\text { review }\end{array}$ & $\begin{array}{l}\text { Evidence } \\
\text { summary }\end{array}$ & Guidance & $\begin{array}{l}\text { Case } \\
\text { studies }\end{array}$ \\
\hline Health, Wellbeing and Open Space & 2003 & OpenSpace (Morris, 2003) & $\checkmark$ & & & \\
\hline The Value of Public Space & 2004 & $\begin{array}{l}\text { Commission for Architecture and the } \\
\text { Built Environment Space (CABE Space, } \\
\text { 2004) }\end{array}$ & $\checkmark$ & & & \\
\hline Green Infrastructure Guide & 2008 & $\begin{array}{l}\text { North West Green Infrastructure Think } \\
\text { Tank (NWGITT, 2008) }\end{array}$ & & & $\checkmark$ & $\checkmark$ \\
\hline Green Infrastructure Guidance & 2009 & Natural England (Natural England, 2009) & & & $\checkmark$ & $\checkmark$ \\
\hline $\begin{array}{l}\text { Community Green: Using Local Spaces to } \\
\text { Tackle Inequality and Improve Health }\end{array}$ & 2010 & CABE Space (CABE Space, 2010) & & $\checkmark$ & & \\
\hline Benefits of Green Infrastructure & 2010 & Forest Research (Forest Research, 2010) & $\checkmark$ & & & \\
\hline $\begin{array}{l}\text { Multifunctional Urban Green } \\
\text { Infrastructure }\end{array}$ & 2010 & $\begin{array}{l}\text { Chartered Institution of Water and } \\
\text { Environmental Management (CIWEM, } \\
\text { 2010) }\end{array}$ & & $\checkmark$ & & $\checkmark$ \\
\hline Green Infrastructure in Urban Areas & 2011 & $\begin{array}{l}\text { Royal Institution of Chartered Surveyors } \\
\quad(\text { RICS, 2011) }\end{array}$ & & $\checkmark$ & & $\checkmark$ \\
\hline Economic Benefits of Greenspace & 2012 & Forestry Commission (Saraev, 2012) & $\checkmark$ & & & \\
\hline $\begin{array}{l}\text { Green Space Design for Health and } \\
\text { Well-Being }\end{array}$ & 2012 & $\begin{array}{l}\text { Forestry Commission (Shackell and } \\
\text { Walter, 2012) }\end{array}$ & & & $\checkmark$ & $\checkmark$ \\
\hline $\begin{array}{l}\text { Microeconomic Evidence for the Benefits } \\
\text { of Investment in the Environment }\end{array}$ & 2012 & Natural England (Sunderland, 2012) & $\checkmark$ & & & \\
\hline $\begin{array}{l}\text { The Multi-Functionality of Green } \\
\text { Infrastructure }\end{array}$ & 2013 & European Commission (SfEP, 2012) & $\checkmark$ & & & \\
\hline $\begin{array}{l}\text { Planning for a Healthy Environment: } \\
\text { Green Infrastructure Guide }\end{array}$ & 2012 & $\begin{array}{l}\text { Town and Country Planning Association } \\
\text { and Royal Society of Wildlife Trusts } \\
\text { (TCPA and RSWT, 2012) }\end{array}$ & & $\checkmark$ & $\checkmark$ & \\
\hline Trees in the Townscape & 2012 & $\begin{array}{l}\text { Trees and Design Action Group (TDAG, } \\
\text { 2012) }\end{array}$ & & & $\checkmark$ & $\checkmark$ \\
\hline $\begin{array}{l}\text { Air Temperature Regulation by Trees and } \\
\text { Green Infrastructure }\end{array}$ & 2013 & $\begin{array}{l}\text { Forest Research (Doick and Hutchings, } \\
\text { 2013) }\end{array}$ & $\checkmark$ & & & \\
\hline $\begin{array}{l}\text { Green Infrastructure's Contribution to } \\
\text { Economic Growth: A Review }\end{array}$ & 2013 & $\begin{array}{l}\text { Eftec and Sheffield Hallam University } \\
\text { (Eftec and SHU, 2013) }\end{array}$ & $\checkmark$ & & & $\checkmark$ \\
\hline Urban Green Infrastructure & 2013 & $\begin{array}{l}\text { Parliamentary Office of Science and } \\
\text { Technology (POST, 2013) }\end{array}$ & $\checkmark$ & & & \\
\hline $\begin{array}{l}\text { Cities Alive: Rethinking Green } \\
\text { Infrastructure }\end{array}$ & 2014 & Arup (Arup, 2014) & & $\checkmark$ & $\checkmark$ & $\checkmark$ \\
\hline $\begin{array}{l}\text { Microeconomic Evidence for the Benefits } \\
\text { of Investment in the Environment } 2\end{array}$ & 2014 & $\begin{array}{l}\text { Natural England (Rolls and Sunderland, } \\
\text { 2014) }\end{array}$ & $\checkmark$ & & & \\
\hline Trees in Hard Landscapes & 2014 & $\begin{array}{l}\text { Trees and Design Action Group (TDAG, } \\
\text { 2014) }\end{array}$ & & & $\checkmark$ & $\checkmark$ \\
\hline Demystifying Green Infrastructure & 2015 & $\begin{array}{l}\text { UK Green Building Council (UKGBC, } \\
\text { 2015) }\end{array}$ & & $\checkmark$ & $\checkmark$ & $\checkmark$ \\
\hline Cities, Green Infrastructure and Health & 2015 & $\begin{array}{l}\text { Landscape Institute (Kirby and Russell, } \\
\text { 2015) }\end{array}$ & $\checkmark$ & & & \\
\hline Green Bridges Guide & 2015 & $\begin{array}{l}\text { Landscape Institute (Landscape Institute, } \\
\text { 2015) }\end{array}$ & & & $\checkmark$ & $\checkmark$ \\
\hline $\begin{array}{l}\text { Natural Capital: Investing in a Green } \\
\text { Infrastructure for a Future London }\end{array}$ & 2015 & Greater London Authority (GLA, 2015) & & $\checkmark$ & $\checkmark$ & $\checkmark$ \\
\hline $\begin{array}{l}\text { The Evidence Base for Linkages between } \\
\text { Green Infrastructure, Public Health and } \\
\text { Economic Benefit }\end{array}$ & 2015 & $\begin{array}{l}\text { Government of Victoria (Bowen and } \\
\text { Parry, 2015) }\end{array}$ & $\checkmark$ & & & \\
\hline
\end{tabular}

session provided an opportunity for participants to discuss one of three questions for $20 \mathrm{~min}$ each before moving tables.

In total, 70 delegates attended the two events from a mix of universities and public sector research organisations $(n=34)$, consultancy and practice $(n=12)$, local and central government $(n=17)$ and non-governmental organisations (NGOs) $(n=7)$. The names of the organisations are provided in the supplementary data.

\section{Results}

\subsection{What evidence is being presented in the grey literature?}

The vast majority of the academic research presented in the grey literature related to the benefits, or ecosystem services, provided by GI (Tables 2 and 3). None of the academic evidence presented related to the governance, long-term 


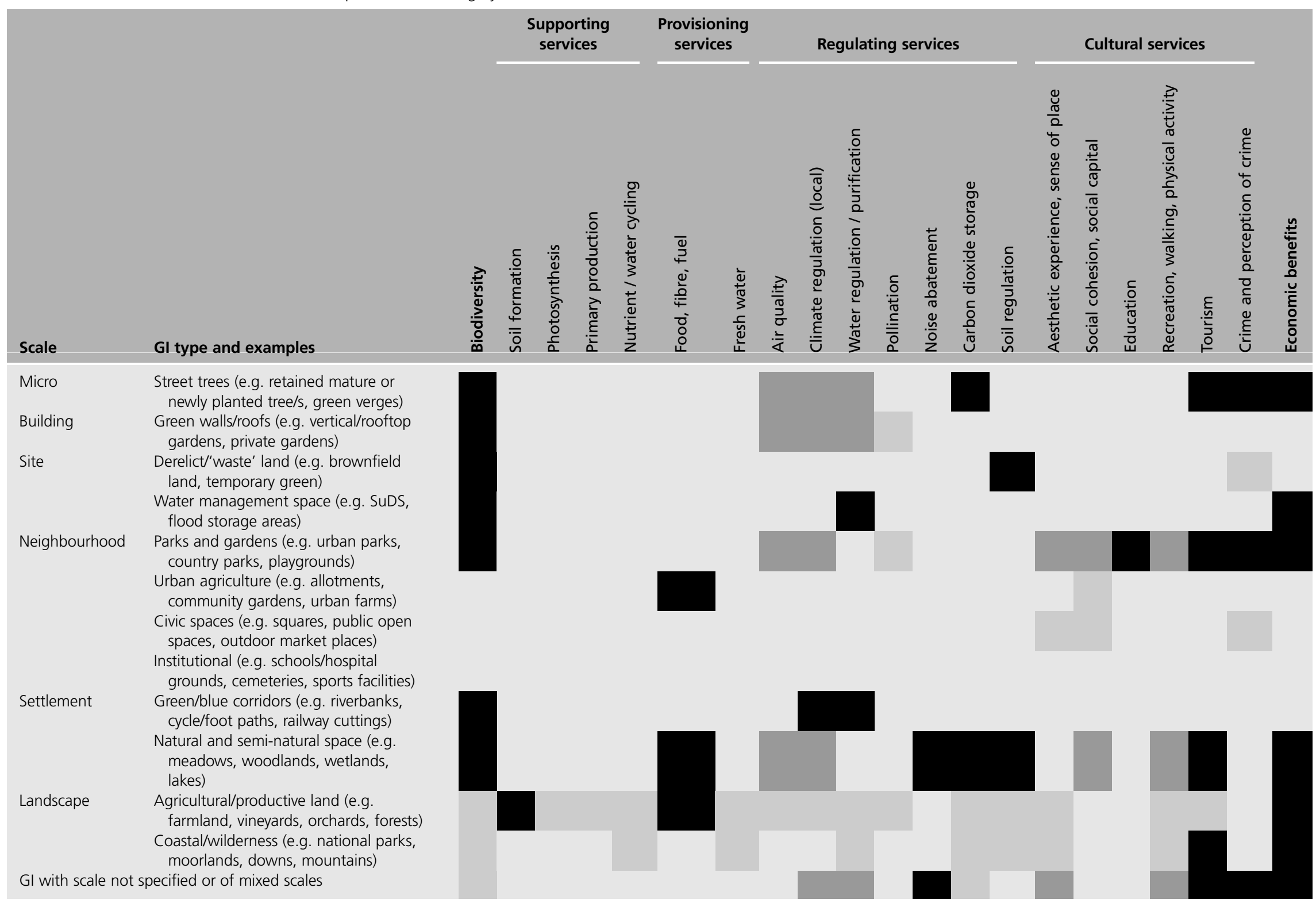

Mid grey, evidence in academic literature but largely absent from grey literature; Dark grey, academic evidence reported in some grey literature; Black, academic evidence featured in a range of grey literature 
Table 3. Overview of the evidence for each ecosystem service presented in the grey literature

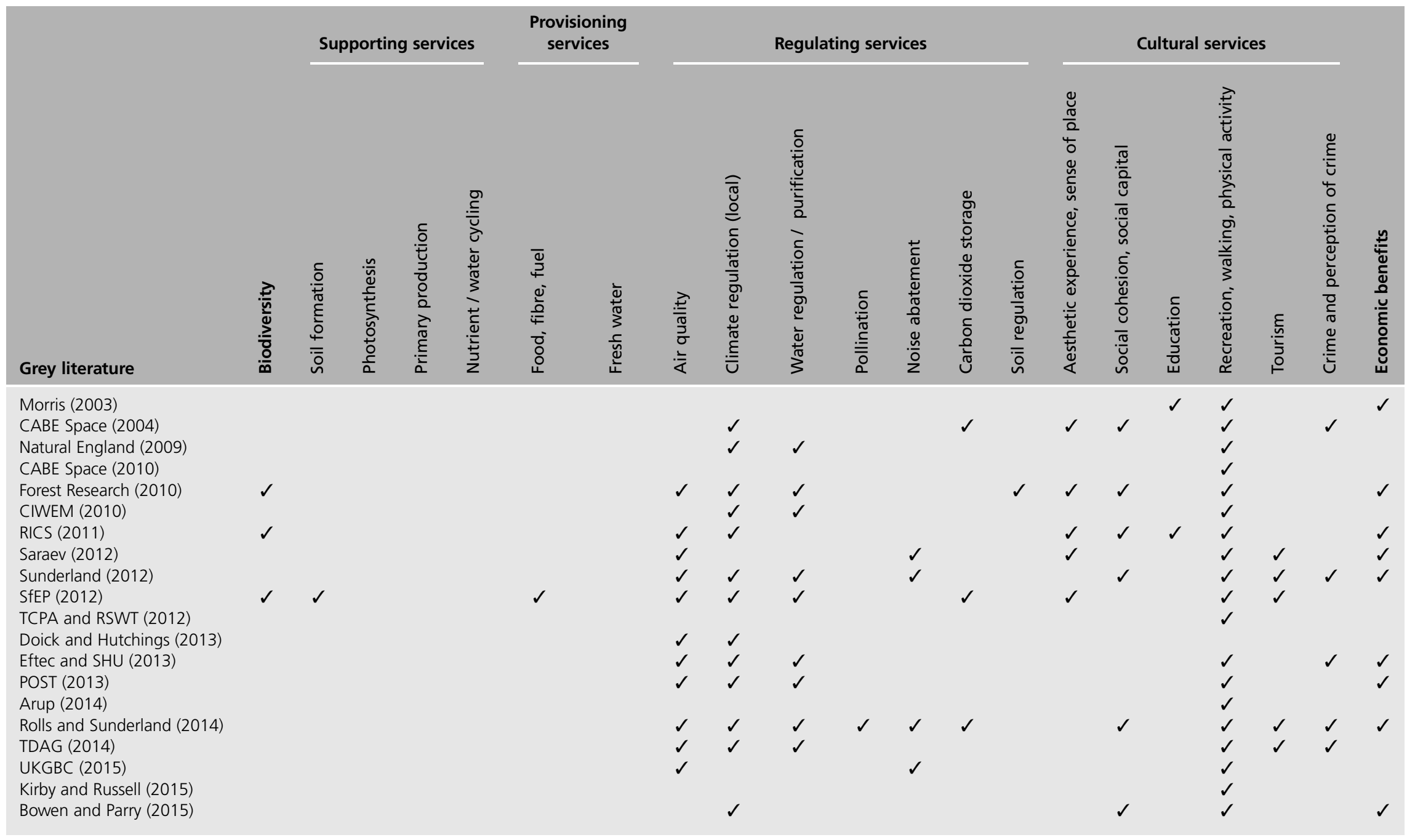


maintenance or strategic planning of GI. Where implementation was covered in the documents, this primarily used evidence from practice (e.g. case studies). This may reflect the differences in maturity of these areas of research so perhaps research examining GI planning and implementation (e.g. Mell, 2014) may begin to be incorporated into the grey literature in the future.

Looking first at biodiversity, only five sources cite the benefits of particular GI features for protecting or enhancing biodiversity (Forest Research, 2010; RICS, 2011; Rolls and Sunderland, 2014; SfEP, 2012; Sunderland, 2012). Substantial evidence indicates that urban areas with greater amounts of GI, which is well connected internally and to the surrounding countryside and includes native species and sensitive management practices, are more biodiverse than areas without these features (Natural England, 2014), so it is interesting that this is not well represented in much of the grey literature.

Similarly, very limited evidence is included in the grey literature on the ability of GI to provide supporting or provisioning services, both of which are restricted in the urban environment (UKNEA, 2011). Supporting ecosystem services are those that underpin the other services, and include soil formation, water and nutrient cycling, and photosynthesis. Only one document highlighted the role of forests in soil and peat formation (SfEP, 2012). Much of the research activity related to urban soils has focused on soil contamination or sealing. Although this clearly impacts on urban soil function and associated services, the focus has primarily been on the risk that such contamination may pose to human or ecological receptors (e.g. Giusti, 2013). The role of GI in water cycling, primarily through flood and surface water runoff, has received considerable attention in the grey literature (see regulating services in Table 2).

Provisioning services include the supply of food, fuel, timber and clean water. Again, the evidence on water quality is related to flood risk management (see Table 2). There is some evidence in the academic literature related to the benefits of urban agriculture (e.g. Bendt et al., 2013; Church et al., 2015), but this is not represented in the grey literature. However, in these studies the outcomes are often centred on improved nutrition, community cohesion and other social benefits as opposed to providing food per se (see cultural services in Table 2).

Regulating services that improve or modify aspects of the environment, enhance safety and quality of life or improve our ability to adapt to climate change receive considerable attention in the grey literature. Numerous sources present evidence that trees and, to a lesser extent, green roofs can improve air quality by intercepting particulates or absorbing gaseous pollutants (e.g. Forest Research, 2010; POST, 2013). Only a few sources acknowledge that trees can also have a negative impact on air quality (RICS, 2011; Sunderland, 2012; TDAG, 2014).

The role of GI in reducing air and surface temperatures through evapotranspiration and shade provision is also highlighted. This primarily relates to trees, green roofs and greenspaces, although some sources refer to GI more generally (e.g. CIWEM, 2010; Rolls and Sunderland, 2014).

Substantial attention is also given to the role of GI in water regulation. The grey literature highlights the benefits of GI for stormwater management, via reduced surface water runoff and improved rainwater retention, by increasing vegetation cover across the urban environment; specifically with green roofs and trees (e.g. Doick and Hutchings, 2013; NE, 2009). Interestingly, although much of the grey literature refers to the ability of GI to manage water it often does not specifically cite the effectiveness of sustainable drainage systems (SuDS). Only three documents discuss the efficacy of SuDS in managing flood risk (CIWEM, 2010; Rolls and Sunderland, 2014; Sunderland, 2012). This may be because the evidence has only looked at specific components of GI as opposed to a SuDS approach that may incorporate many different green and blue features or it may be an attempt to avoid technical language. It could also be that this review focused on grey literature concerned with GI whereas documents specific to particular functions and targeted at a more specialised audience, such as SuDS (e.g. Woods Ballard et al., 2015), were omitted.

Several types of GI, including trees, green roofs, SuDS, wetlands and woodlands, are also recognised for their ability to improve water quality by preventing pollutants from entering rivers and streams as well as contributing to flood management (e.g. SfEP, 2012; TDAG, 2014).

The use of vegetation as a barrier against noise is long established, but this is not reflected a great deal in the grey literature, with only a few sources highlighting this function (Rolls and Sunderland, 2014; Saraev, 2012; Sunderland, 2012, UKGBC, 2015).

There is some recognition in the grey literature that trees and woodland can provide some carbon dioxide storage benefits (e.g. CABE Space, 2004; SfEP, 2012). Only two sources mention soil regulation (Forest Research, 2010) or pollination (Rolls and Sunderland, 2014). Although this may be due to the relative immaturity of the research into the benefits of GI in these regulating services compared with the other ecosystem services, it is also likely to be a reflection of the greater attention in the UK on the challenges of flood risk management and air quality.

Almost all of the pieces of grey literature reviewed cite evidence that GI can deliver cultural ecosystem services. 
These provide people with opportunities for recreation, rest, relaxation and spiritual enhancement. Numerous sources present evidence that the 'greenness' of urban environments or having views of green and blue settings reduces blood pressure and stress, and improves mood, attention span, cognitive function and self-esteem (e.g. Arup, 2014; Morris, 2003). Several also point to the importance of greenspaces and natural features in contributing to a sense of place (e.g. Forest Research, 2010; RICS, 2011), or greenspaces (e.g. CABE Space, 2004; Rolls and Sunderland, 2014) and community gardens (Bowen and Parry, 2015) in increasing social interaction and, as a result, social cohesion and capital. However, the educational benefits from GI in restoring people's connection to nature are rarely reported (Morris, 2003; RICS, 2011).

The benefits of GI on physical and mental health outcomes are also a strong component of many documents. Some relate physical activity or walking levels to proximity or access to GI (e.g. CABE Space, 2010; Kirby and Russell, 2015), whereas others explicitly measure the use of GI in some way (e.g. Bowen and Parry, 2015; Forest Research, 2010). Others specifically relate contact with nature or greater levels of biodiversity to improved mental health (Rolls and Sunderland, 2014; UKGBC, 2015).

Cited health outcomes in children include reduced symptoms of attention deficit disorder and attention deficit hyperactivity disorder (e.g. Bowen and Parry, 2015; CABE Space, 2004), greater development of interpersonal skills, levels of creative play (Forest Research, 2010; TCPA and RSWT, 2012) and physical activity, and lower body mass indices (Bowen and Parry, 2015; UKGBC, 2015).

Several pieces of grey literature cite evidence that the presence of GI is associated with lower levels of anti-social behaviour and perception of crime (e.g. CABE Space, 2010; TDAG, 2014), and that urban GI can attract new visitors (e.g. Saraev, 2012; SfEP, 2012; TDAG, 2014). Conversely, some report that trees can be associated with greater criminality (Eftec and SHU, 2013) and greenspaces can increase the fear of antisocial behaviour (Rolls and Sunderland, 2014).

Some grey literature presents evidence that the ecosystem services provided by GI result in economic benefits. This is primarily focused on health and wellbeing outcomes from improved air quality (e.g. Eftec and SHU, 2013; SfEP, 2012) and physical activity (Bowen and Parry, 2015; Saraev, 2012), as well as stormwater management (SfEP, 2012; Sunderland, 2012), carbon dioxide storage (e.g. Eftec and SHU, 2013; Sunderland, 2012) and tourism (e.g. Morris, 2003; Rolls and Sunderland, 2014). Some grey literature also cites evidence of increased commercial and residential property values (e.g. Eftec and SHU, 2013; RICS, 2011), economic activity (Morris, 2003) and job creation (Eftec and SHU, 2013; Forest Research, 2010) related to GI.

\subsection{How is evidence used by the Gl community?}

To supplement the findings of the literature review, the workshops explored how participants access and use evidence related to GI. Generally, participants felt that the evidence in grey literature was more usable and useful to them than that in academic literature. This is to be expected among practitioners as grey literature is generally purposely written for non-academic audiences (MacDonald et al., 2010). However, the participants talked of an overload of both academic evidence and grey literature. This is a common complaint across grey literature in general (Lawrence et al., 2014). The GI grey literature was highly regarded for its presentation style, including the more accessible language, the provision of clear overviews that could be read quickly, the authoritative evidence base, the use of case studies and the distillation of evidence into guidance. Similarly, the collation of evidence from a range of disciplines was also seen as useful, as was its applicability to a range of disciplines. This may explain why academic participants also found the grey literature helpful, especially those relatively new to GI (e.g. public health professionals) or those who were felt to be particular target audiences (e.g. developers). Trust was also important; participants valued grey literature from an organisation with a good reputation and that provided balance to arguments as opposed to being a 'biased' advocacy document.

However, there were some concerns that the quality, and thus usefulness, of grey literature varies. For example, some was seen as a duplication of previous documents, presenting the same evidence or case studies. The time lag in producing grey literature was also seen as problematic as this often means that it is out of date by the time of publication. Here, it was felt that evidence could be obtained earlier in the research process either directly from researchers or through the experiences of colleagues.

There was debate about the value of academic evidence. Some participants, often academics, said they would only use academic evidence. Others, mainly practitioners, said they never use it as they found it too detailed and would be more likely to trust evidence from colleagues - a finding in common with the use of grey literature in general (Lawrence et al., 2014). Many of the limitations of academic research seemed to stem from end-users not being involved in the research process from the start. There was a mismatch between the evidence valued by practitioners and that for academics; for example, reviews are useful for practitioners but are not prioritised by academics. Similarly, there was frustration that the larger, prestigious grants are available for basic research that will take time to reach the maturity required for implementation, and that new technologies are developed but there is often little robust long-term monitoring and evaluation of how successful these are in practice. 
Participants highlighted a wide range of difficulties with accessing and using evidence in both the grey literature and academic articles, broadly grouped as follows.

- Multi-disciplinarity. Although accepted as a strength of GI, the diverse, prolific and dispersed nature of evidence as well as differences in language across the disciplines, organisations, networks and publishers means that evidence is difficult to locate and interpret.

- Uncertainty over the quality of evidence. Participants, particularly those from practice or working across unfamiliar disciplines, expressed difficulty in assessing the quality of the evidence in both academic and grey literature, citing a lack of the necessary skills.

- Gaps, or perceived gaps, in the evidence. Participants also perceived gaps in the evidence presented in grey literature, but they were often unsure as to whether these were genuine gaps in research or whether the evidence was simply omitted from the grey literature (e.g. if it was not supportive of GI). Some felt that some of this evidence is available but needs to be promoted or disseminated more effectively by academics or through a third party.

- Structural barriers to access. Some participants, again mainly practitioners, highlighted barriers including insufficient time to search and review academic evidence, the language used as well as the cost of these papers and some grey literature (e.g. that produced by professional bodies). There appeared to be little awareness of openaccess journal papers or university publication repositories.

Many of these are common problems for practitioners, particularly the time to sift through evidence, difficulty in assessing quality and the cost of academic articles (Lawrence et al., 2014; MacDonald et al., 2010). Participants felt that it was important to support practitioners in prioritising academic evidence. This could include a central website to collect and organise GI evidence, grey literature that better represents a number of disciplines and functions of GI (see Section 3.3) and making better use of the community to share learning, for example, through study tours and visits, placements or secondments between academia and practice. Academics also highlighted that there is no mechanism for them to easily trace how their research is used and that it would be beneficial for practitioners to communicate when research findings were used in practice.

\subsection{Which disciplines are involved in the translation of evidence?}

The review identified a large number of disciplines and sectors that are involved in publishing evidence and guidance on GI for a range of audiences. These were further explored in the workshops.

Ecologists and landscape architects appear to be significant advocates, the former primarily concerned with the benefits from nature, as opposed to the benefits of GI for nature. Landscape architects seem to be more explicitly focused on urban GI and providing guidance for the delivery of highquality GI. In addition, urban trees and greenspaces have also benefited from strong advocacy by particular organisations (e.g. Trees and Design Action Group (TDAG) and Commission for Architecture and the Built Environment (CABE) Space). As the authorship of the grey literature demonstrates, other disciplines (e.g. surveyors, water engineers) are represented, but to a much lesser degree. However, as already noted this may be because the more specialist grey literature was omitted from this review.

Participants generally felt that the multi-disciplinary nature of GI was key to its success but there were contrasting views on whether this is reflected in the grey literature. Some participants felt that it is, citing the multiple benefits of GI that often feature in the grey literature. Others felt that, although that might be the intention, the discipline of the author, organisation or funder often influences the content. One suggestion was for authors to acknowledge and identify the disciplines that have not yet been engaged and provide a clear rationale for how and why disciplines could come together at project inception.

Linked to this there are challenges inherent in working across disciplinary boundaries. Although viewed as essential for the success of GI, the reality is that research and practice often operate in single disciplinary silos. Academics highlighted disincentives for multi-disciplinary and applied research in terms of career progression and attracting funding, which generally reward specialism and basic research; this is well documented (van Rijnsoever and Hessels, 2011). Participants felt that both the academic and grey literature could better emphasise the interconnectedness of the different features and functions of GI.

Alongside these concerns there was also recognition that specialised, targeted literature could be beneficial, highlighting the importance of detailed knowledge. Thus, some participants considered that no one piece of grey literature can address different audiences competently and documents should therefore be targeted to a specific discipline. Conversely, others felt that grey literature targeted in this way may give a narrow view of GI. The logical synthesis is perhaps that there needs to be 'nested' grey literature: some documents that cover overarching issues and perspectives, and others that are more targeted to disciplines or GI features.

The review suggested that some disciplines key to the delivery of GI were less visible than may have been expected. With the exception of the Town and Country Planning Association (TCPA), which has been a longstanding champion of GI, planners and development surveyors appear to be underrepresented in the grey literature. Participants also felt that 
some disciplines were under-represented both as suppliers of evidence (e.g. public health professionals, geographers, geologists, air quality experts and ecologists) and audiences for it (e.g. planners, surveyors, economists, public health and transport professionals, water and coastal engineers, architects and urban designers). What is particularly interesting here is that organisations such as Natural England and the Royal Society of Wildlife Trusts have been advocates of GI but that the grey literature often omits ecological evidence, focusing instead on the wider benefits of nature. Audiences felt to be missing generally consisted of those seen as essential to the delivery of GI.

Participants also felt that a number of sectors were underrepresented or not targeted specifically in the grey literature, including policy makers, central government, decision makers in local authorities, those in economic development or responsible for managing GI, and the general public.

Participants suggested a number of routes by which grey literature could be improved. Crucially, as already mentioned, the emphasis was on tailoring grey literature to specific audiences, both across sectors and specific disciplines or groups of disciplines, and collaborating with them to ensure it meets their needs. Examples included short briefing papers for senior managers in local authorities or policy makers. This is good practice in science communication (Bultitude, 2011) and grey literature in general (MacDonald et al., 2010).

The importance of networks and other organisations such as professional bodies was also highlighted. These have a role in ensuring the evidence is fit for purpose, addressing differences in language and terminology, publicising new evidence or grey literature, and reviewing new publications to address some of the uncertainty regarding the quality of research, which can be an effective way of improving the quality of grey literature (Lawrence et al., 2014).

\subsection{What are the gaps in evidence related to GI?}

The review of the grey literature provided insight into the evidence reaching practitioner audiences. However, it highlighted some gaps related to the ability of certain GI features to deliver a range of ecosystem services (particularly SuDS and soft landscaping other than trees (NE, 2014)) and a lack of longitudinal studies examining the health outcomes of GI interventions.

Participants in the workshops also highlighted a number of specific gaps in the evidence. In contrast to the gaps identified above, these primarily concerned the effectiveness of GI or more operational aspects. For example, as already mentioned, participants expressed frustration that funding is often available to implement GI or research new benefits of GI but not for high-quality monitoring and evaluation of what works (and what doesn't) particularly over the long time periods that it can take vegetation to establish or behaviours to settle. This was particularly relevant, as highlighted earlier, when investigating causal relationships between GI and health outcomes, without which it is difficult to convince public health professionals. Linked to this, providing monetised benefits of GI was seen as critical to demonstrate cost effectiveness, particularly to property developers, engineers and transport professionals, local authorities and central government.

On a more operational level, participants felt that much research has focused on individual GI features, often performing one function, with little emphasis on the design and performance of these features as a multi-functional network across a range of spatial scales. Frustration was also expressed that even in areas with strong GI policy the potential benefits are undermined by poor-quality delivery (e.g. in new development) or maintenance. It was felt that this could be improved through better understanding of the decision-making process and enhanced knowledge, skills and competencies of key decision makers.

\subsection{How can research evidence be made more useful to practitioners?}

Academic evidence was often respected in terms of methodology and robustness but was often seen as divorced from the needs of practitioners. The workshop participants discussed a range of ideas for making research evidence more useful or relevant to those in practice, primarily concentrated on collaboration or funding. First, early collaboration between academia and practice was seen as essential for researchers to understand what evidence can be used; for example, the type of evidence that planning officers can use in decision making. This collaboration should then continue throughout the research process, including funding decisions, so that all partners are involved in setting research questions, planning, designing and producing research, including the publishing and dissemination of research findings. Policy makers particularly should be brought into the research process as, at the moment, research findings do not transfer well into policy. Often, the best examples of effective grey literature are where policy makers and researchers collaborate (MacDonald et al., 2010). Areas of good practice were highlighted, for example, by the Blue-Green Cities research project (BGC, 2017), which brought multiple stakeholders together throughout the project via a 'learning and action alliance'. There was a feeling that the generation of research impact is too often an afterthought for academics and should be embedded in the research design. Although acknowledged as challenging, participants felt that research teams should be multi-disciplinary, including the involvement of disciplines representative of practitioners. There was frustration that GI research often omits those from built environment disciplines who may have a greater understanding of delivery.

There was a feeling that funding structures and opportunities should be improved to enable more effective collaboration. For example, many sources of funding in the UK do not allow 
non-academic partners to be funded, which severely limits their ability to engage with research, especially where NGOs or public sector bodies are being invited to join multiple bids. There are, however, a number of sources of funding designed to facilitate such collaborations, including those from Innovate UK (e.g. knowledge transfer partnerships) and the Research Councils (e.g. the innovation fund and fellowships).

\section{Conclusions}

This study provides insights into how GI research can be made more relevant to the end-users of the research. The importance of early and sustained collaboration with all the disciplines and sectors necessary to ensure research is relevant and usable was emphasised by academics, practitioners and policy makers. In particular, built environment professions are under-represented in the grey literature and the generation of knowledge, and yet they are critical to the successful delivery of GI. Those responsible for grey literature should develop it in conjunction with the intended audiences and consider producing 'nested' literature for different audiences, for example, overarching evidence summaries versus detailed evidence. All those involved in GI research should make the case for long-term monitoring and evaluation of the outcomes of GI interventions. Such studies should do more than consider individual features of GI and instead examine a range of GI functions across different spatial scales to build an evidence base of GI as a truly multifunctional network.

\section{Acknowledgements}

This work was funded through the Natural Environment Research Council Green Infrastructure Innovation Fund (grant NE/N016971/1). The authors would also like to thank the participants of the workshops for engaging with the events and sharing their experiences and insights.

\section{REFERENCES}

Arup (2014) Cities Alive: Rethinking Green Infrastructure. Arup, London, UK.

Bendt P, Barthel S and Colding J (2013) Civic greening and environmental learning in public-access community gardens in Berlin. Landscape and Urban Planning 109(1): 18-30.

BGC (Blue-Green Cities) (2017) http://www.bluegreencities.ac.uk/ (accessed 24/07/2017).

Bowen KJ and Parry M (2015) The Evidence Base for Linkages between Green Infrastructure, Public Health and Economic Benefit. Government of Victoria, Melbourne, VIC, Australia.

Bultitude K (2011) The why and how of science communication. In Science Communication (Rosulek P (ed.)). European Commission, Pilsen, Czech Republic. See https://www.ucl.ac.uk/sts/staff/ bultitude/KB_TB/Karen_Bultitude_-_Science_Communication_ Why_and_How.pdf (accessed 01/11/2016).

CABE (Commission for Architecture and the Built Environment) Space (2004) The Value of Public Space: How High Quality Parks and Public Spaces Create Economic, Social and Environmental Value. CABE Space, London, UK.

CABE Space (2010) Community Green: Using Local Spaces to Tackle Inequality and Improve Health. CABE Space, London, UK.
Church A, Mitchell R, Ravenscroft N and Stapleton LM (2015) 'Growing your own': a multi-level modelling approach to understanding personal food growing trends and motivations in Europe. Ecological Economics 110: 71-80, https://doi.org/10.1016/ j.ecolecon.2014.12.002.

CIWEM (Chartered Institution of Water and Environmental Management) (2010) Multifunctional Urban Green Infrastructure. CIWEM, London, UK.

DCLG (Department for Communities and Local Government) (2016) Planning Practice Guidance. Green Infrastructure. DCLG, London, UK. See http://planningguidance.communities.gov.uk/blog/ guidance/natural-environment/green-infrastructure/ (accessed 03/11/2016).

de Vries S, Verheij RA, Groenewegen PP and Spreeuwenberg P (2003) Natural environments - healthy environments? An exploratory analysis of the relationship between greenspace and health Environment and Planning A 35(10): 1717-1731.

Doick K and Hutchings T (2013) Air Temperature Regulation by Urban Trees and Green Infrastructure. Forest Research, Farnham, UK.

EC (European Commission) (2013) Green Infrastructure (GI) Enhancing Europe's Natural Capital. EC, Brussels, Belgium. See http://eur-lex.europa.eu/legal-content/EN/TXT/?uri= CELEX:52013DC0249 (accessed 03/11/2016).

Eftec and SHU (Sheffield Hallam University) (2013) Green Infrastructure's Contribution to Economic Growth: A Review. A Final Report for Defra and Natural England. Eftec, London, UK.

Forest Research (2010) Benefits of Green Infrastructure. Forest Research, Farnham, UK.

Freer-Smith PH, Holloway S and Goodman A (1997) The uptake of particulates by an urban woodland: site description and particulate composition. Environmental Pollution 95(1) $27-35$

Giusti L (2013) The chemistry and parent material of urban soils in Bristol (UK): implications for contaminated land assessment. Environmental Geochemistry and Health 35(1): 53-67.

GLA (Greater London Authority) (2015) Natural Capital: Investing in a Green Infrastructure for a Future London. Green Infrastructure Task Force, London, UK.

GLNS (Grey Literature Network Service) (2012) GLNS, Amsterdam, the Netherlands. See http://www.greynet.org/greynethome.html (accessed 03/11/2016).

Jerome G (2017) Defining community-scale green infrastructure. Landscape Research 42(2): 223-229.

Kazemi F, Beecham S and Gibbs J (2011) Streetscape biodiversity and the role of bioretention swales in an Australian urban environment. Landscape and Urban Planning 101(2): $139-148$.

Kirby V and Russell S (2015) Cities, Green Infrastructure and Health. Landscape Institute, London, UK.

Landscape Institute (2015) Green Bridges Guide. Landscape Institute, London, UK

Lawrence A, Houghton J, Thomas J and Weldon P (2014) Where is the Evidence? Realising the Value of Grey Literature for Public Policy and Practice. Swinburne Institute for Social Research, Melbourne, VIC, Australia.

MacDonald BH, Wells PG, Cordes RE et al. (2010) The use and influence of information produced as grey literature by international, intergovernmental marine organisations: overview of current research. In Grey Literature in Library and Information Studies (Farace DJ and Schöpfel J (eds)). Walter de Gruyter, Berlin, Germany, pp. 167-180.

Mell IC (2014) Aligning fragmented planning structures through a green infrastructure approach to urban development in the UK and USA. Urban Forestry \& Urban Greening 13(4): 612-620. 
Morris N (2003) Health, Wellbeing and Open Space. Open Space, Edinburgh, UK.

Natural England (2009) Green Infrastructure Guidance. Natural England, London, UK.

Natural England (2014) Ecosystem Services Transfer Toolkit. Natural England, London, UK. See http://publications.naturalengland.org. uk/publication/5890643062685696 (accessed 03/11/2016).

NRW (Natural Resources Wales) (2015) Wales Green Infrastructure Forum. NRW, Cardiff, UK. See http://naturalresources. wales/people-and-communities/green-spaces/wales-greeninfrastructure-forum/?lang=en (accessed 03/11/2016).

NWGITT (North West Green Infrastructure Think Tank) (2008) North West Green Infrastructure Guide. NWGITT, Liverpool, UK.

POST (Parliamentary Office of Science and Technology) (2013) Urban Green Infrastructure. POST, London, UK, POSTNote 448.

RICS (Royal Institution of Chartered Surveyors) (2011) Green Infrastructure in Urban Areas. RICS, London, UK.

Rolls S and Sunderland T (2014) Microeconomic Evidence for the Benefits of Investment in the Environment 2. Natural England, Bristol, UK.

Saraev V (2012) Economic Benefits of Greenspace. Forestry Commission, Edinburgh, UK.

Scottish Government (2011) Green Infrastructure: Design and Placemaking. Scottish Government, Edinburgh, UK. See http://www.gov.scot/resource/doc/362219/0122541.pdf (accessed 24/07/2017).

SfEP (Science for Environment Policy) (2012) The Multi-Functionality of Green Infrastructure. In-Depth Report. European Commission, DG Environment News Alert Service, Brussels, Belgium.
Shackell A and Walter R (2012) Greenspace Design for Health and Well-Being. Practice Guide. Forestry Commission, Edinburgh, UK. Sunderland T (2012) Microeconomic Evidence for the Benefits of Investment in the Environment. Natural England, Bristol, UK.

Tallis M, Taylor G, Sinnett D and Freer-Smith PH (2011)

Estimating the removal of atmospheric particulate pollution by the urban tree canopy of London, under current and future environments. Landscape and Urban Planning 103(2): $129-138$.

TCPA and RSWT (Town and Country Planning Association and Royal Society of Wildlife Trusts) (2012) Planning for a Healthy Environment: Green Infrastructure Guide. TCPA, London, UK.

TDAG (Trees and Design Action Group) (2012) Trees in the Townscape. TDAG, London, UK.

TDAG (2014) Trees in Hard Landscapes. TDAG, London, UK.

UKGBC (UK Green Building Council) (2015) Demystifying Green Infrastructure. UKGBC, London, UK.

UKNEA (UK National Ecosystem Assessment) (2011) The UK National Ecosystem Assessment: Synthesis of the Key Findings. UNEP-WCMC, Cambridge, UK.

van Rijnsoever FJ and Hessels LK (2011) Factors associated with disciplinary and interdisciplinary research collaboration. Research Policy 40(3): 463-472.

Woods Ballard B, Wilson S, Udale-Clarke H et al. (2015) Ciria Report C753: The SuDS Manual. Construction Industry Research and Information Association, London, UK. See http://www.ciria. org/Memberships/The_SuDs_Manual_C753_Chapters.aspx (accessed 24/07/2017). 